\title{
Rapid determination of orotic acid in urine by a fast liquid chromatography/tandem mass spectrometric method
}

\author{
Giancarlo la Marca ${ }^{1 \star}$, Bruno Casetta ${ }^{2}$ and Enrico Zammarchi ${ }^{1}$ \\ ${ }^{1}$ Metabolic and Neuromuscolar Unit, 1st Pediatric Clinic, A. Meyer Children's Hospital, University of Florence, 50132 Florence, Italy \\ ${ }^{2}$ Applied Biosystems, 20052 Monza, Milan, Italy
}

Received 9 December 2002; Revised 10 February 2003; Accepted 10 February 2003

\begin{abstract}
Quantification of orotic acid (uracil-6-carboxylic acid) in urine is an important tool to diagnose some inherited diseases, such as urea cycle disorder (OTCD) and hereditary orotic aciduria. New rapid analytical methods are necessary to provide high-throughput orotic acid analyses. A new analytical method has been developed for the rapid analysis of orotic acid in urine by liquid chromatography coupled with ion spray tandem mass spectrometry (LC/MS/MS). After a sample dilution 1:20, the analysis was performed in the selected reaction monitoring mode in which orotic acid was detected through the transition $\mathrm{m} / \mathrm{z} 155$ to 111 . The retention time was $3.9 \mathrm{~min}$ in a $4.5-\mathrm{min}$ analysis. Daily calibration between $0.5-5.0 \mu \mathrm{mol} / \mathrm{L}$ of orotic acid, corresponding to $10-100 \mu \mathrm{mol} / \mathrm{L}$ in urine before the 1:20 dilution, offered consistent linearity and reproducibility. Interassay coefficient of variance (c.v.) was $4.97 \%$ at a mean concentration of $10.99 \mu \mathrm{mol} / \mathrm{L}$. The sensitivity and specificity of tandem mass spectrometry permitted a high volume of analyses of orotic acid. The sample preparation is simple, inexpensive and not time demanding. Copyright (C) 2003 John Wiley \& Sons, Ltd.
\end{abstract}

The analysis of orotic acid (OA) is used in clinical chemistry to diagnose some diseases associated with urea cycle disorders; ornithine transcarbamylase deficiency $(\mathrm{OTCD})^{1}$ is the most common, and also hereditary orotic aciduria. ${ }^{2}$ The urea cycle has three roles: it produces urea as the waste product incorporating nitrogen not used for biosynthetic purposes, it is involved in the biochemical reactions that degrade and synthesise arginine de novo, and it plays a fundamental role in $\mathrm{pH}$ homeostasis. ${ }^{3}$

Ornithine transcarbamylase, a mitochondrial matrix enzyme, catalyses the synthesis of citrulline from carbamyl phosphate and ornithine. OTCD male patients show classical clinical symptoms such as vomiting, lethargy, and confusion; clinical laboratory indications are high values of glutamine and ammonia, low citrulline, and high urinary excretion of orotic acid. Also, female manifesting carriers generally have higher than normal values of urinary orotic acid excretion due to $X$-inactivation.

Hereditary orotic aciduria is a pyrimidine synthesis defect caused by uridine- 5 '-monophosphate (UMP) synthase deficiency. ${ }^{4}$ This multienzyme catalyses the synthesis of UMP starting from orotic acid via orotidine-5'-monophosphate. Some characteristic clinical features are anaemia, hematuria, pallor, diarrhoea, retarded and poor development, while laboratory indications include very high urinary orotic acid excretion.

${ }^{*}$ Correspondence to: G. la Marca, Metabolic and Neuromuscolar Unit, 1st Pediatric Clinic, A. Meyer Children's Hospital, University of Florence, 50132 Florence, Italy.

E-mail: giancalm@yahoo.com
Therefore, determination of orotic acid levels in urine is becoming an assay routinely performed in clinical analysis. ${ }^{5-13}$ To date, orotic acid has been determined mostly by liquid chromatography (HPLC) with UV detection at $275 \mathrm{~nm} .{ }^{14}$ This approach is quite cumbersome in the subsequent integration and interpretation process. Signals from a 'normal' specimen are quite difficult to quantify since the LC-UV peaks are very close to the baseline (lack of adequate sensitivity) and are sometimes not sufficiently resolved from other endogenous components owing to the nonspecific wavelength chosen for detection. In addition the chromatographic run is time demanding.

In this paper we evaluate the possibility to take advantage of tandem mass spectrometry ${ }^{15}$ (MS/MS) as the basis for a rapid method for determination of OA in urine with very simple preparation, which could be a candidate for highthroughput routine analyses. The main criteria in developing a robust high-throughput analytical method center around minimal sample preparation, no derivatization, high sensitivity and specificity, high throughput capability, and minimal instrument maintenance. It was hoped that such a method would provide a suitable tool for a large-scale investigation.

\section{EXPERIMENTAL}

\section{Materials}

An orotic acid standard was purchased from Sigma-Aldrich (Steinheim, Germany), and a stock solution was made in 
water (corresponding to $1 \mathrm{mg} / \mathrm{mL} \mathrm{OA}$ ). Successive dilutions were made using a $50 \%$ aqueous solution of acetonitrile containing $5 \mathrm{mmol} / \mathrm{L}$ ammonium acetate. All chemicals and solvents were of the highest purity available from commercial sources and were used without further purification.

\section{Sample preparation}

Urine samples were prepared by dilution (1 vol. urine+ 19 vol. water containing $0.1 \%$ formic acid). For the purposes of this study, urine samples with different creatinine concentrations were spiked with known amounts of orotic acid. $2 \mu \mathrm{L}$ of the diluted samples were injected for the LC/MS/MS experiments.

\section{Methods}

An Applied Biosystems-Sciex (Toronto, Canada) API 2000 bench-top triple-quadrupole mass spectrometer, equipped with a TurboIonSpray source, was employed for this study. The TurbolonSpray source was operated in negative ion mode with a needle potential of $-4800 \mathrm{~V}$ and with a 'turbo' gas flow of $10 \mathrm{~L} / \mathrm{min}$ of air heated at $300^{\circ} \mathrm{C}$ (nominal heatinggun temperature). Mass calibration and resolution adjustments on the resolving quadrupoles were performed automatically by using a $10^{-4} \mathrm{~mol} / \mathrm{L}$ PPG solution introduced via the built-in infusion pump. The peak width was set on both resolving quadrupoles at $0.7 \mathrm{Th}$ (measured at half height) for all MS and MS/MS experiments.

Collision-activated dissociation (CAD) MS/MS was performed in the LINAC Q2 collision cell, operating with 10 mTorr pressure of nitrogen as collision gas. The declustering potential (DP) and collision energy (CE) were automatically optimized for orotic acid using the instrument software. The resulting DP was $-10 \mathrm{~V}$, and optimal CE was found to be $12 \mathrm{eV}$ (laboratory frame).

MS and MS/MS spectra were collected in continuous flow mode by connecting the infusion pump directly to the TurbolonSpray source. A standard solution of $10 \mathrm{ng} / \mu \mathrm{L}$ of $\mathrm{OA}$ in an aqueous solution of $50 \%$ acetonitrile containing $5 \mathrm{mmol} / \mathrm{L}$ ammonium acetate was infused at $10 \mu \mathrm{L} / \mathrm{min}$. The quantitation experiments were performed using a series 1100 Agilent Technologies (Waldbronn, Germany) CapPump coupled to an Agilent Micro ALS autosampler, both fully controlled from the API 2000 datasystem. Liquid chromatography was performed using a Phenomenex Luna C18 $5 \mu \mathrm{m}$, $3 \times 150 \mathrm{~mm}$ HPLC column (Chemtek-Analitica, Anzola Emilia, Italy). Column flow rate was $0.45 \mathrm{~mL} / \mathrm{min}$ using an aqueous solution of $60 \%$ acetonitrile containing $0.1 \%$ formic acid. The eluent from the column was directed to the TurbolonSpray probe with a split ratio of 1:5.

The acquired data were processed using the Analyst 1.1 proprietary software including the 'Explore' option (for chromatographic and spectral interpretation) and the 'Quantitate' option (for quantitative information generation).

\section{RESULTS AND DISCUSSION}

Figure 1 shows the structure of orotic acid. Figure 2 shows the mass spectrum collected via infusion through the TurbolonSpray probe at $10 \mu \mathrm{L} / \mathrm{min}$ of a solution of $10 \mathrm{ng} / \mu \mathrm{L}$ of orotic<smiles>O=C(O)c1cc(=O)[nH]c(=O)[nH]1</smiles>

Figure 1. Structure of uracil-6-carboxylic acid (orotic acid).

acid. The $[\mathrm{M}-\mathrm{H}]^{-}$ion is clearly observed at $m / z$ 155.1. Figure 3 shows the MS/MS spectrum obtained by fragmenting the $[\mathrm{M}-\mathrm{H}]^{-}$precursor ion of OA using the conditions described above. From these experiments, the MS/MS transition chosen for the quantitative experiments (selected reaction monitoring, SRM) is $m / z 155.1 \rightarrow 111.1$. Figure 4 displays a typical calibration curve obtained in the concentration range 0.5$5.0 \mu \mathrm{mol} / \mathrm{L} \quad(10-100 \mu \mathrm{mol} / \mathrm{L}$ before the 1:20 dilution). Figure 5 shows the SRM chromatograms obtained for a standard solution $(1.0 \mu \mathrm{mol} / \mathrm{L}$, left) and a urine sample (right) containing $1.6 \mu \mathrm{mol} / \mathrm{L}$ diluted 20-fold. Chromatographic conditions were chosen in order to minimise the run time (less than $4.5 \mathrm{~min}$ ) since the outstanding specificity is provided by the MS/MS detection. Comparison of the two panes of Fig. 5 indicates that the bulk of the matrix does not lead to any extra chromatographic peaks by this method.

The sample dilution ratio (20:1) and injection volume ( $2 \mu \mathrm{L})$ were selected in order to not overload the chromatographic column even after a considerable number of sample injections (the equivalent of $0.1 \mu \mathrm{L}$ of original urine is introduced through each single injection); the injection sample volume was selected after several trials. The dilution was made with water and no organic solvent, resulting in a solvent with weaker elution capabilities than the LC eluent used for reversed-phase LC; this was intended to pack the injected sample plug at the front end of the column. The outcome is that the column shows robust performance as long as only $0.1 \mu \mathrm{L}$ of the original urine is loaded $(2 \mu \mathrm{L}$ of $20 \times$ diluted sample), whatever the salt concentration in the specimen (expressed by the creatinine concentration in the present application).

Concerning calibration, it was considered that external calibration with aqueous standards was sufficient for the present purpose. To test this, a range of urine samples with very different densities and creatinine concentrations were spiked with $10 \mu \mathrm{mol} / \mathrm{L}$ of OA. Samples were processed and quantitated by comparison with aqueous standards as described in the Experimental section (results are reported without normalisation for the creatinine content). As an example, Table 1 reports the data obtained for three samples, with low $(0.58 \mathrm{mmol} / \mathrm{L})$, medium $(2.3 \mathrm{mmol} / \mathrm{L})$ and high $(3.74 \mathrm{mmol} / \mathrm{L})$ creatinine concentrations.

Including all the other samples examined, discrepancies between spiked values and measured values using external calibration with aqueous standards were within $6 \%$. These data lead to the conclusion that a simple external calibration with aqueous standard should be viable in these experimental conditions, for present purposes.

In order to assess the robustness of the method, several urine samples with different creatinine contents were processed several times, resulting an intra-day reproduci- 


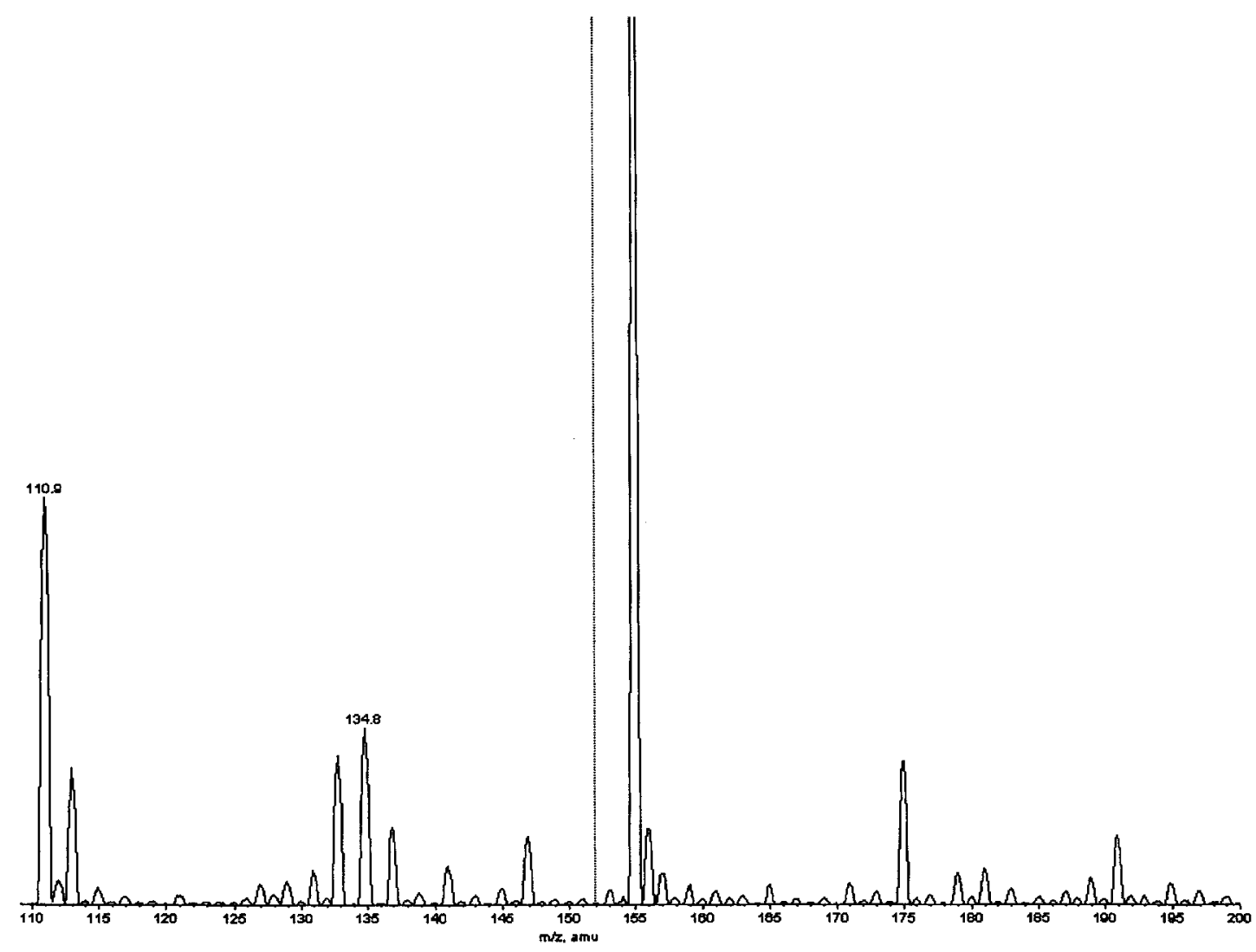

Figure 2. Mass spectrum in negative-ion mode recorded by infusing a solution of $10 \mathrm{ng} / \mu \mathrm{L}$ of orotic acid.

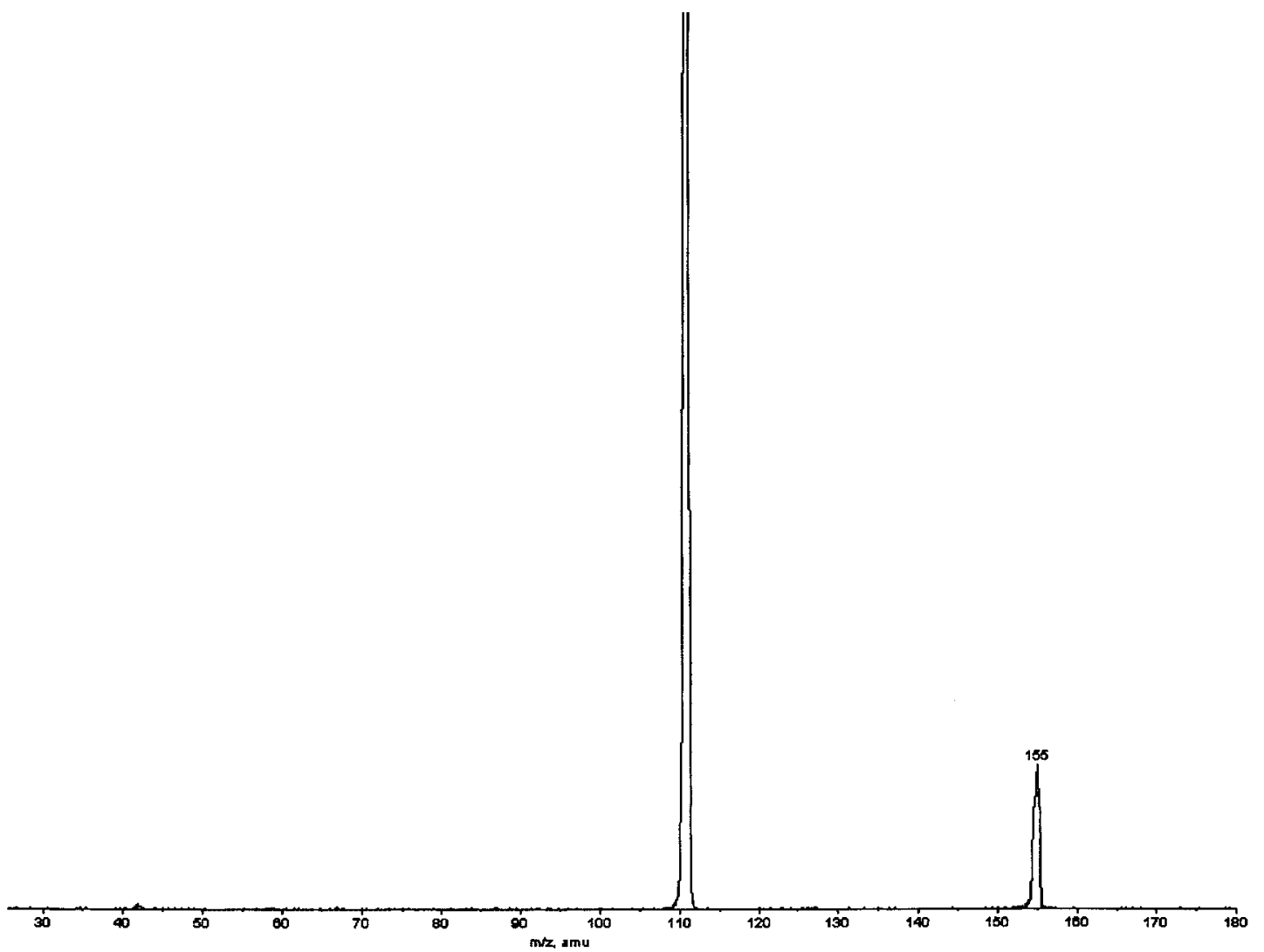

Figure 3. MS/MS spectrum obtained by fragmenting the $[M-H]^{-}$precursor ion $(m / z 155.1)$ of $O A$ in negative-ion mode with a collision energy of $12 \mathrm{eV}$. 


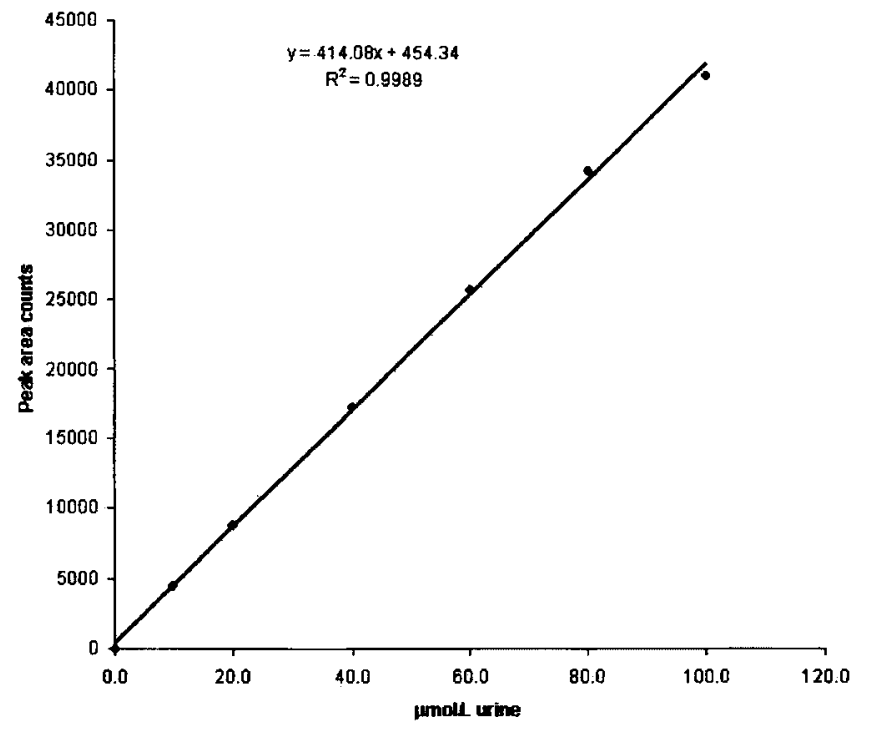

Figure 4. Typical calibration curve obtained in the concentration range $0.5-5.0 \mu \mathrm{mol} / \mathrm{L}$ of orotic acid, corresponding to $10-100 \mu \mathrm{mol} / \mathrm{L}$ in urine before the 1:20 dilution.
Table 1. Determination of $O A$ in urine with different creatinine concentrations, against aqueous calibration standards without internal calibration

\begin{tabular}{|c|c|c|c|}
\hline $\begin{array}{l}\text { OA concentration } \\
\mu \mathrm{mol} / \mathrm{L}\end{array}$ & $\begin{array}{c}\text { Creatinine } \\
\text { concentration } \\
\mathrm{mmol} / \mathrm{L}\end{array}$ & $\begin{array}{l}\text { Determina- } \\
\text { tion against } \\
\text { aq. standard } \\
\text { (no IS) } \mu \mathrm{mol} / \\
\text { L (\%) }\end{array}$ & $\begin{array}{r}\text { Ratio Read/ } \\
\text { Calculated }\end{array}$ \\
\hline 1.02 & 0.58 & 1.00 & 98.0 \\
\hline 11.02 & 0.58 & 10.44 & 94.7 \\
\hline 0.97 & 2.3 & 0.97 & 100.0 \\
\hline 10.97 & 2.3 & 10.3 & 93.9 \\
\hline 1.36 & 3.74 & 1.4 & 102.9 \\
\hline 11.36 & 3.74 & 11.52 & 101.4 \\
\hline
\end{tabular}

bility below $6.4 \%$ for values above $5 \mu \mathrm{mol} / \mathrm{L}$ (see Table 2 ). In an inter-day reproducibility test, reproducibility values better than $5 \%$ were obtained (see Table 3).

With the proposed experimental parameters, the estimated limits of detection (signal-to-noise $(\mathrm{S} / \mathrm{N})=3$ ) in urine were $0.15 \mu \mathrm{mol} / \mathrm{L}$. With the same experimental parameters, the

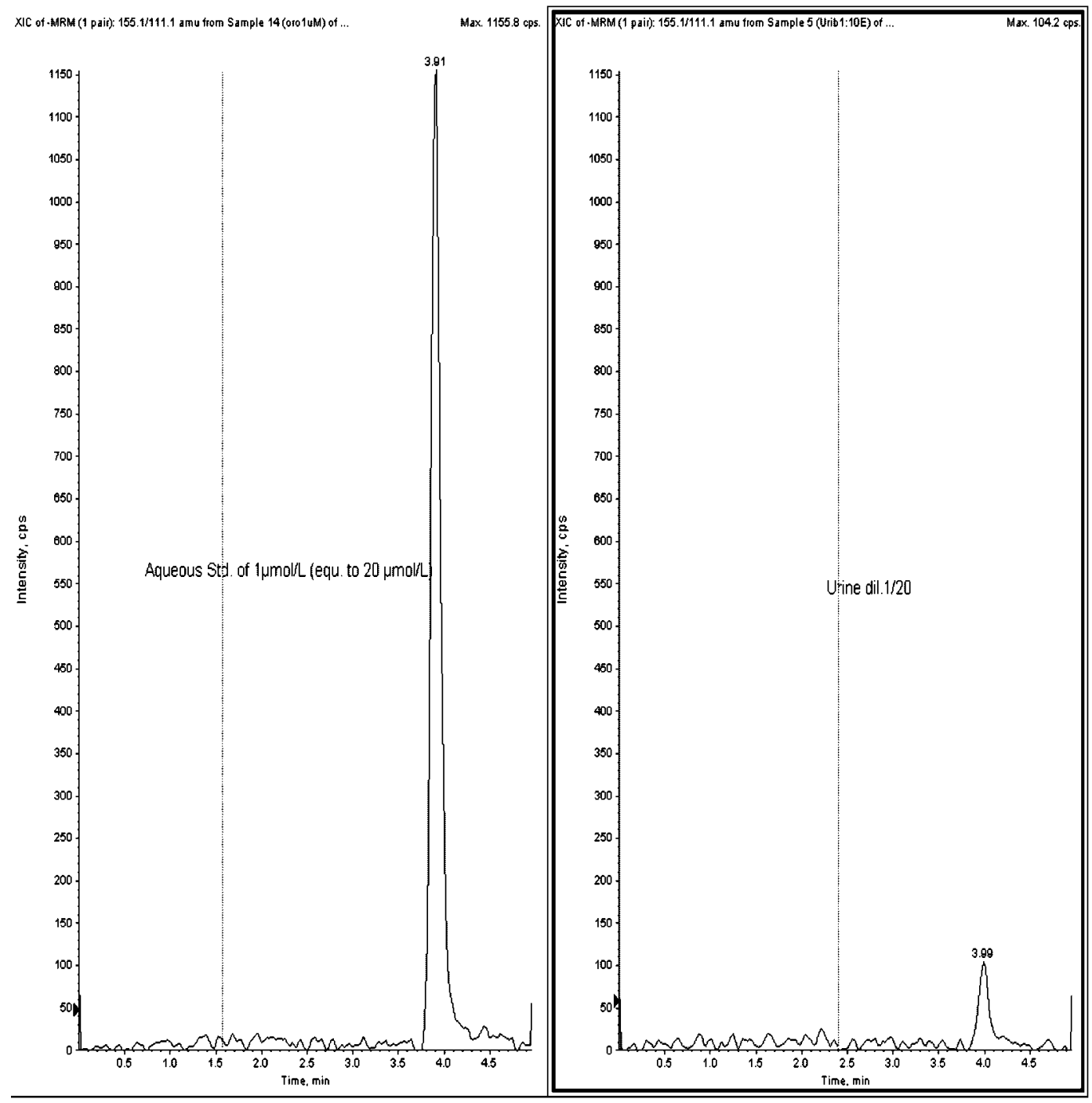

Figure 5. SRM chromatograms obtained for a standard solution $(1.0 \mu \mathrm{mol} / \mathrm{L}$, left $)$ and a urine sample (right) containing $1.6 \mu \mathrm{mol} / \mathrm{L} \mathrm{OA}, 20$ times diluted. 
Table 2. Intra-day reproducibility for OA-spiked urine with different creatinine concentrations. (Quantitation against aqueous calibration standards)

\begin{tabular}{|c|c|c|c|c|c|c|c|}
\hline \multicolumn{4}{|c|}{ Urine with $21 \mu \mathrm{mol} / \mathrm{L}$, low creatinine } & \multicolumn{4}{|c|}{ Urine with $20.03 \mu \mathrm{mol} / \mathrm{L}$, medium creatinine } \\
\hline & \multicolumn{3}{|l|}{20.18} & & \multicolumn{3}{|l|}{20.58} \\
\hline & \multicolumn{3}{|l|}{20.01} & & \multicolumn{3}{|l|}{21.12} \\
\hline & \multicolumn{3}{|l|}{20.83} & & \multicolumn{3}{|l|}{21.12} \\
\hline & \multicolumn{3}{|l|}{21.49} & & \multicolumn{3}{|l|}{19.70} \\
\hline & \multicolumn{3}{|l|}{21.16} & & \multicolumn{3}{|l|}{20.76} \\
\hline & \multicolumn{3}{|l|}{21.00} & & \multicolumn{3}{|l|}{18.80} \\
\hline Average & 20.78 & Accuracy & 98.65 & Average & 20.35 & Accuracy & 101.58 \\
\hline St. Dev. & & 0.57 & & St. Dev. & 0.92 & & \\
\hline c.v. $\%$ & 2.77 & & & c.v. \% & 4.52 & & \\
\hline \multicolumn{4}{|c|}{ Urine with $11 \mu \mathrm{mol} / \mathrm{L}$, low creatinine } & \multicolumn{4}{|c|}{ Urine with $10.03 \mu \mathrm{mol} / \mathrm{L}$, medium creatinine } \\
\hline & \multicolumn{3}{|c|}{11.75} & \multicolumn{3}{|c|}{9.16} & \\
\hline & \multicolumn{3}{|l|}{11.47} & \multicolumn{3}{|c|}{8.58} & \\
\hline & \multicolumn{3}{|l|}{11.78} & \multicolumn{3}{|c|}{9.36} & \\
\hline & \multicolumn{3}{|l|}{11.35} & \multicolumn{3}{|c|}{8.82} & \\
\hline & \multicolumn{3}{|l|}{10.27} & \multicolumn{3}{|c|}{9.76} & \\
\hline & \multicolumn{3}{|l|}{12.04} & & \multicolumn{3}{|l|}{10.16} \\
\hline Average & 11.44 & Accuracy & 104.02 & Average & 9.31 & Accuracy & 92.79 \\
\hline St. Dev. & & 0.62 & & St. Dev. & 0.59 & & \\
\hline c.v. $\%$ & 5.46 & & & c.v. $\%$ & 6.31 & & \\
\hline \multicolumn{4}{|c|}{ Urine with $0.6 \mu \mathrm{mol} / \mathrm{L}$, low creatinine } & \multicolumn{4}{|c|}{ Urine with $21.36 \mu \mathrm{mol} / \mathrm{L}$, high creatinine } \\
\hline & 0.85 & & & & 20.37 & & \\
\hline & 0.39 & & & & 20.18 & & \\
\hline & 0.65 & & & & 19.39 & & \\
\hline & 0.56 & & & & 21.43 & & \\
\hline & 0.51 & & & & 20.57 & & \\
\hline & 0.66 & & & & 21.64 & & \\
\hline Average & 0.60 & Accuracy & 100.61 & Average & 20.59 & Accuracy & 96.42 \\
\hline St. Dev. & & 0.16 & & St. Dev. & 0.83 & & \\
\hline c.v. $\%$ & 25.68 & & & c.v. $\%$ & 4.04 & & \\
\hline
\end{tabular}

Table 3. Example of Intraday reproducibility. Urine with $11 \mu \mathrm{mol} / \mathrm{L}$ orotic acid. (Quantitation against calibration aqueous standard)

\begin{tabular}{llr}
\hline Day 1 & 11.41 & \\
Day 2 & 11.62 & \\
Day 3 & 11.22 & \\
Day 4 & 10.19 & \\
Day 5 & 10.54 & \\
Day 6 & 10.94 & \\
Average & 10.99 & Accuracy \\
St. Dev. & & 0.55 \\
CV \% & 4.95 & \\
\hline
\end{tabular}

limits of quantitation in urine $(\mathrm{S} / \mathrm{N}=10)$ were $0.383 \mu \mathrm{mol} / \mathrm{L}$. No deterioration in column efficiency was observed after analysis of 200 urine samples.

\section{CONCLUSIONS}

The proposed method is characterised by a fast and very simple sample preparation. Calibration is made externally with aqueous standards with no need for expensive isotopically labeled standards. Instrumental analysis time is less than $4.5 \mathrm{~min}$. Fast chromatography, combined with the specificity provided by tandem mass spectrometric detection, allows for a fast, robust and specific procedure for OA determination.
Several factors have made it possible to develop this simple application. These include the good MS/MS sensitivity in negative-ion mode even with the presence of formic acid $(0.1 \%)$ in the chromatographic eluent, the MS/MS specificity guaranteed even at such low $m / z$ values by the resolution set for both quadrupoles (peak widths $0.7 \mathrm{Th}$, FWHM), and the robustness of the TurbolonSpray interface, which makes possible the injection of crude samples after a simple dilution, even without the need for an internal standard. The latter aspect is possible provided that the chromatographic retention factor (k-factor) is large enough relative to the column void volume.

The detection limit of $0.15 \mu \mathrm{mol} / \mathrm{L}$ of OA in urine should not be regarded as the ultimate figure since an increase of sensitivity could be expected by downsizing the LC column diameter. However, the value achieved here seems to fulfill the sensitivity requirements of the present application, and it has been decided to stay with the $3.0-\mathrm{mm}$ column since it is more robust for several hundreds of injections. Switching to a smaller column, e.g., $1 \mathrm{~mm}$ i.d., should increase the sensitivity by a factor of about one order of magnitude.

\section{REFERENCES}

1. Pelet A, Rotig A, Bonaiti-Pellie C, et al. Hum. Genet. 1990; 84: 167.

2. Simmonds HA, Webster DR, Becroft DM, Potter CF. Eur. J. Clin. Invest. 1980; 10: 333. 
3. Bean ES, Atkinson DE. J. Biol. Chem. 1984; 259: 1552.

4. Scriver CR, Beaudet, Valle, Sly, Childs, Kinzler, Vogelstein. The Metabolic and Molecular Bases of Inherited Disease (VIIIth edn). McGraw-Hill: New York, (2) 2667.

5. Rogers LE, Porter F. Pediatrics 1968; 42: 423.

6. Jeevanandam M, Shoemaker J, Horowitz G, Lowry S, Brennan M. Metabolism 1985; 34: 325.

7. Glasgow A. Am. J. Clin. Pathol. 1982; 77: 452.

8. Van Gennip A, Van Bree-Blom E, Grift J, De Bree P, Wadman S. Clin. Chim. Acta 1980; 104: 227.
9. Kidouchi K, Ohba S, Nakamura C, Katoh T, Kibe T, Wada Y. Int. J. Pur. Pyr. Res. 1992; 2(Suppl. 1): 58.

10. Jakobs C, Sweetman L, Nyhan W, Gruenke L, Craig J, Wadman S. Clin. Chim. Acta 1984; 143: 123.

11. McCann M, Thompson M, Gueron I, Tuchman M. Clin. Chem. 1995; 41: 739.

12. Carpenter K, Potter M, Hammond J, Wilcken B. J. Inherit. Metab. Dis. 1997; 20: 354

13. Sevcik J, Adam T, Sazel V. Clin. Chim. Acta 1997; 259: 73.

14. Banditt P. J. Chromatogr. B Biomed. Appl. 1994; 660: 176.

15. Niessen WMA. J. Chromatogr. A 1998; 828: 401. 